\title{
He Said, She Said: The Impact of Candidate Gender in Negative Campaigns
}

\author{
Stephen C. Craig
}

\section{University of Florida}

\section{Paulina S. Rippere}

\author{
Jacksonville University
}

The elections of 1992 were proclaimed by the media (and some Woman. During an era when female candidates for high political office were still something of a novelty, Dianne Feinstein and Barbara Boxer (both Democrats) won U.S. Senate races against male Republican opponents, thereby making California the first state to be represented in the Senate by two women. In their benchmark study of campaign advertising, much of Ansolabehere and Iyengar's (1995) experimental work focused on these two races and one more, the 1990 contest in which incumbent Pete Wilson narrowly defeated Feinstein for governor. Although the major-party nominees in all three elections were of opposite gender, the authors were more concerned with assessing the effects of campaign advertising generally, and of negative advertising in

A preliminary version of this paper was presented at the 2013 Annual Meetings of the American Political Science Association. We want to thank Roger Austin for his assistance in designing this experiment, Jim Kitchens for facilitating the Internet survey used in our analysis, Marissa Silber Grayson for her contributions to two companion papers (Craig, Rippere, and Grayson 2012, 2014), and three anonymous reviewers for their comments on earlier drafts.

Published by Cambridge University Press 1743-923X/16 \$30.00 for The Women and Politics Research Section of the American Political Science Association.

(C) The Women and Politics Research Section of the American Political Science Association, 2016 doi:10.1017/S1743923X15000550 
particular, in races where one of the contestants happened to be a woman. The broader question of whether going negative is more (or less) effective for women or men was left unanswered and is the focus of our article.

Although women continue to be underrepresented in American public life, the political landscape has changed dramatically since 1992. More women are running for office today, and often winning, in part because they have become increasingly adept at the art of negative campaigning. That, at least, is one conclusion that might be drawn based on the insights of political insiders. Whether or not the overall tone of political discourse is more negative than in the past, ${ }^{l}$ there is little doubt that negativity has become a staple of campaigns at all levels. While positive ads may be an important element in one's overall communications package (Franz et al. 2008), attacks are more likely to be viewed as game changers or game deciders, especially for challengers, who are said to have little chance of winning unless they go negative (Geer 2006; Mattes and Redlawsk 2014).

All of this would seem to make negativity an indispensable weapon in the arsenal of female candidates, who are more likely than men to be challengers and therefore to lack the resources (such as money) that usually come with incumbency. The catch is that going negative may pose a special risk for women because it violates expectations about appropriate behavior that are rooted in the traditional gender stereotypes held by some voters even in the 21st century (Dolan 2014; but see Brooks 2013). As Trent, Friedenberg, and Denton (2011, 164-65) explain, "[w]hen women speak, they are expected to exhibit characteristics such as sensitivity to the needs of others, concern for family and relationships, compassion, emotionality, affection, and nurturing. They are not expected to employ harsh language or to be overtly assertive, either verbally or physically." 2

Politicians whose behavior does not conform to these expectations are thought to risk having their message rejected by voters (Trent, Friedenberg, and Denton 2011, 165). As a result, political consultants once advised women - and perhaps some still do - that attacking their

1. No existing dataset of which we are aware provides a clear answer to this question (for different perspectives, see Buell and Sigelman 2008; Fowler and Ridout 2012; Geer 2012; Lau and Pomper 2004; West 2014). Negative campaigning, however, is more likely than in the past to be covered by the media (Lau and Rovner 2009; also see Geer 2012; Ridout and Smith 2008) and thus to be noticed by voters, contributing to an impression of growing negativity.

2. For a contrary view, see Schneider and Bos (2014). Hayes (2011) concluded that partisan stereotypes are more powerful than gender stereotypes and likely to remain so in an era of heightened polarization between Republican and Democratic elites. 
opponent could generate a backlash and jeopardize their chances for electoral success (Gordon, Shafie, and Cigler 2003, 36), especially if the attack is delivered personally by the candidate and delivered in a shrill or strident manner (Nelson 2009, 58-59). ${ }^{3}$ Nevertheless, a review of televised campaign ads posted on YouTube, as well as some academic research (for example, see Herrnson and Lucas 2006; Nelson 2009; Panagopoulos 2004), confirms the willingness of many female candidates to go negative. Whether they lose more than they gain in doing so is inconclusive. ${ }^{4}$

In this article, we examine gender differences in the effectiveness of one attack made by a challenger against an incumbent of the opposite sex in a hypothetical race for the U.S. House of Representatives. Our interest, however, is not limited to the attack itself but extends to the question of how candidates should respond when they are attacked - and whether certain types of responses work better for men than they do for women, and vice versa, in terms of mitigating the damage inflicted by an initially successful negative ad. We know very little about the relative effectiveness of different types of responses and almost nothing about whether such effectiveness is a function of candidate gender. This article represents a modest first step in trying to rectify that situation.

\section{NEGATIVE ADS AND CANDIDATE GENDER}

No campaign ad is effective simply because of its negativity. In addition to being well-crafted (see Craig and Hill 2011, 136-37), a negative ad should work best when it is hard-hitting (Fridkin and Kenney 2008, 2011), relevant (not tangential to "governing performance" or dealing with matters of little concern to voters; Fridkin and Kenney 2008, 697), more or less accurate (the facts presented may be exaggerated, distorted, or presented out of context, but they should not be demonstrably false; Johnson 2007, 59), specific about what the target has done wrong (broad accusations of misbehavior are not sufficient), and offered in support of a credible opponent (candidates with little chance of winning will have trouble getting voters' attention). ${ }^{5}$

3. As Nelson $(2009$, 59) pointed out, female speech is sometimes devalued by describing it as "shrill" when the same words delivered by a man would not be viewed as anything atypical.

4. Brooks (2010, 2011, 2013); Dinzes, Cozzens, and Manross (1994); Fridkin, Kenney, and Woodall (2009); Gordon, Shafie, and Cigler (2003); Hitchon and Chang (1995); and Krupnikov and Bauer (2014).

5. These factors are discussed more fully in Craig, Rippere, and Grayson (2014). 
What is the impact of campaign advertising on voter decision making? Whereas candidates, their consultants, party leaders, and political journalists believe that it is often substantial and occasionally decisive, academic studies have yielded mixed results regarding the effectiveness of political advertising generally, and of negative ads in particular. It seems likely that the inconsistent findings of this literature are due in some degree to the fact that negativity lies in the eye of the beholder; that is, "whether a tactic, a candidate, or a campaign is [perceived as] negative depends on whose ox is being gored" (Sigelman and Kugler $2003,144)$. In particular, research shows that partisans react differently to attacks coming from the other side than they do to accusations made by candidates of their own party (Ansolabehere and Iyengar 1995; Geer 2006; Iyengar, Jackman, and Hahn 2008; Stevens et al. 2015).

We suspect that partisanship also has much to do with how voters react to negative ads sponsored by women. As noted earlier, some individuals "may rely heavily on gender stereotypes when evaluating a female candidate who goes on the attack (Gordon, Shafie, and Cigler 2003, 36), withholding their support for women who violate traditional sex role expectations by attacking their opponents during a campaign. This tendency, to the extent that it exists, probably varies across voters, contexts, issues (see Ditonto, Hamilton, and Redlawsk 2014; Dolan 2014; Gordon, Shafie, and Cigler 2003), and other alleged transgressions that form the basis for campaign attacks. But above all else, we anticipate that it will vary with the party affiliation of the candidate. ${ }^{6}$ According to a recent survey experiment by Krupnikov and Bauer (2014), voters are more likely to punish women relative to men (based on gender stereotypes) only when they (a) are seen as having instigated the negativity and (b) represent the opposite party. Setting aside the question of instigation, ${ }^{7}$ we expect a similar result here:

$H_{1}$ : A well-crafted attack by either a man or a woman is more effective among voters who share the attacking candidate's party affiliation.

$\mathrm{H}_{2}$ : Among voters who identify with the opposing/target party (not fellow partisans or independents), attacks by female candidates are less effective than those made by male candidates.

6. This expectation is based on a large body of research, some of it noted above, that shows partisanship to be a critically important perceptual filter through which political information is processed by many citizens. It is probably not the only such filter, of course.

7. This is better investigated within the context of an ongoing dialogue between candidates rather than a single exchange such as the one created for our study. 
It is possible, of course, that shared gender also plays a role. Based on identity politics, one might anticipate that women will respond differently than men to attacks made by a female candidate precisely because the latter is a woman (e.g., Plutzer and Zipp 1996; Rosenthal 1995; Sanbonmatsu 2002). This would presumably make female voters less likely to respond favorably to attacks made by men against women candidates and/or more likely to be moved by attacks made by women against their male opponents. On the other hand, prior research (Dolan 2008, 2014; Dolan and Lynch 2014; Hayes 2011; Sanbonmatsu and Dolan 2009) has found that party stereotypes (and to a lesser extent, incumbency) largely override gender stereotypes in terms of their impact on voter decisions in mixed-gender races. Will we observe a similar imbalance with regard to the relative importance of shared partisanship versus shared gender in shaping citizens' reactions to campaign communications? Playing devil's advocate, our third hypothesis suggests otherwise:

$\mathrm{H}_{3}$ : A well-crafted attack is more effective among voters who share the attacking candidate's gender.

Assuming that an attack inflicts some damage in terms of diminished vote support and lower favorability ratings (and the ad we tested certainly did that), what is the best way for a candidate to respond? One option is to stay on message while ignoring the specific charges. Contrary to what many practitioners believed in the early days of negative TV ads (Johnson-Cartee and Copeland 1991), this is no longer considered to be a wise strategy. A more promising approach involves denial: specifically, if the target can credibly argue that the attack is based on false information, s/he should quickly do so because there is a fairly good chance that the offending campaign will be penalized by voters for its actions (Johnson 2007; Johnson-Cartee and Copeland 1991). ${ }^{8}$

Communications scholars have identified a number of other possible responses, four of which are considered (along with denials) in our analysis:

- counterattacks, the content of which may have little to do with the original attack;

8. Like negativity, what constitutes the "truth" is open to interpretation, even among scholars; see, for example, the different takes on George H.W. Bush's 1988 campaign by Jamieson (1992) and Geer (2006). Denial is probably better for rebutting demonstrably false accusations of personal misconduct than for countering charges that are fundamentally political in nature (e.g., being out of touch with voters, doing the bidding of "special interests," flip-flopping on the issues). 
- mudslinging, a type of counterattack that ignores the original charges and criticizes the opponent for waging a negative campaign, especially if s/he has promised not to do so;

- counterimaging, a positive message that flips the attack on its head by "laying out for the voter a counterproposition to the content of the opponent's negative ad," (e.g., police officers praising the record of someone accused of being soft on crime; see Johnson-Cartee and Copeland 1991, 244); ${ }^{9}$ and

- justifications, which acknowledge the behavior and accept responsibility but attempt to downplay its negative consequences. ${ }^{10}$

Consultants would probably agree with Republican consultant David Hill that in most instances "the best response is to make a counter-charge" (Ansolabehere and Iyengar 1995, 15; Craig and Hill 2011, 141), though our research (Craig, Rippere, and Grayson 2012, 2014) indicates that all of these responses except for accusations of mudslinging are more or less equally effective at mitigating the initial damage done by an attack.

Is this as true for women candidates as it is for men? The literature, which focuses far more on attacks than on responses, provides almost no guidance regarding what gender differences we might expect to find. The same logic that has been applied to attacks might also hold true for counterattacks (including accusations of mudslinging); that is, because of the gender stereotypes held by many voters, there may be a disproportionate risk of backlash for female candidates who respond to negative ads in kind. As noted earlier, however, empirical support for this argument on the attack side is mixed at best. Further, according to Krupnikov and Bauer (2014), opposing partisans often react differently to negativity depending on which candidate is perceived as having cast the first stone. Because the

9. A good example of counterimaging occurred during the 2008 Democratic presidential primary when Hillary Clinton aired the controversial "it's 3 a.m. and something's happening in the world" ad that emphasized, without mentioning his name, her opponent's lack of experience (see https:// www.youtube.com/watch?v=7yr7odFUARg). The Obama campaign answered with an ad that closely resembled Clinton's but conveyed a very different and, we would argue, generally positive message (the implied comparison notwithstanding) suggesting that the best person to answer the phone at 3 a.m. was one who had taken the "correct" positions on Iraq, al-Qaeda, and nuclear disarmament (see https://www.youtube.com/watch? $v=\mathrm{irNLgCP} 37 \mathrm{~m} 0$, both ads accessed March 2, 2016). The counterimaging responses in our experimental manipulations were patterned after the Obama ad, though they clearly lack the latter's powerful visual imagery.

10. Some of these strategies are drawn from the work on "political accounts" (McGraw 1990; McGraw, Best, and Timpone 1995). In addition, the silence option (ignoring the charges, staying on message) can only be tested indirectly - that is, by measuring the impact of an attack prior to the introduction of an active response. Given that the boost provided by any campaign ad is likely to be temporary (Bartels 2014; Gerber et al. 2011; Hill et al. 2013), a more realistic approach would be to examine this impact after a longer time interval than the one used here (see, for example, Weaver, Lariscy, and Tinkham 1999). 
attacker in our simulation is, by definition, the "instigator," there is no reason to anticipate that counterattacks will be less effective for women than for men. Absent any prior studies that might suggest otherwise, we employ the null hypothesis as our benchmark:

$\mathrm{H}_{4}$ : No response type is significantly more (or less) effective for male candidates than for females.

As with attacks $\left(\boldsymbol{H}_{\mathbf{l}}\right)$, we expect partisanship to have a strong influence on the effectiveness of any response ad regardless of the candidate's gender:

$\mathrm{H}_{5}$ : Any response, whether delivered by a man or a woman, is more effective among voters who share that candidate's party affiliation.

However, following $\boldsymbol{H}_{3}$, we also predict that shared gender will have an impact:

$\boldsymbol{H}_{6}$ : Any response, whether delivered by a man or a woman, is more effective among voters who share that candidate's gender.

\section{STUDY DESIGN}

The current study, which is part of a larger project designed to assess the impact of both attacks and responses in political campaigns (Craig, Rippere, and Grayson 2012, 2014; Craig and Rippere 2014), examines 662 voters who completed an Internet survey conducted June 21-24, 2012. Data were provided by qSample (see www.qSample.com), a market research firm that has recruited more than five million individuals to participate in research projects related to video gaming, home building/ contracting, home ownership, issues of particular interest to college students and Baby Boomers, as well as politics. Respondents for our survey were drawn from a national panel of registered voters, geographically balanced by region, whose members engage in ad testing, focus groups, and in-depth interviewing on a range of politically relevant topics. ${ }^{11}$

For our survey experiment, respondents were randomly assigned to one of twenty treatment groups and asked to complete a background questionnaire that measured basic demographics, political knowledge,

11. The sample consisted of $51.8 \%$ women and $48.2 \%$ men; $78.6 \%$ whites and $21.5 \%$ nonwhites; $17.1 \%$ aged $18-29,26.6 \%$ aged $30-44,29.6 \%$ aged $45-59$, and $26.7 \%$ aged 60 and over; $10.7 \%$ high school graduates or less, $26.6 \%$ with some college, $34.6 \%$ college graduates, and $28.1 \%$ with some postgraduate education; $29.3 \%$ self-identified liberals, $21.9 \%$ moderates, $34.3 \%$ conservatives, and $14.5 \%$ other (including $11.8 \%$ who said they "haven't thought much about it"); $40.9 \%$ selfidentified Democrats, $13.6 \%$ "pure" independents, $34.1 \%$ Republicans, and $11.3 \%$ other. 
party identification, and a number of other political orientations. ${ }^{12}$ They were then told to imagine that it was the fall of 2012, and one of the races on their ballot involved a congressional matchup between an incumbent seeking a third term and an experienced challenger who had served in both local office and the state legislature. After reading short biographies of the candidates, ${ }^{13}$ participants were asked to indicate a vote preference ("Based on the information you currently have, which candidate would you vote for if the election were held today?") and to rate each candidate on a 7-point scale ranging from "very unfavorable" (1) to "very favorable" (7); answers to these three questions served as the dependent variables for our analysis. Participants subsequently read what was described as a direct-mail attack ${ }^{14}$ by the challenger and once again registered their vote choice and candidate assessments. Finally, they were given the incumbent's response and answered the vote and candidate questions a third time. ${ }^{15}$

In crafting the attacks, we opted not to employ policy appeals that would likely be viewed through a partisan/ideological lens by many voters (Iyengar, Jackman, and Hahn 2008; also see Druckman, Peterson, and Slothuus 2013; Lavine, Johnson, and Steenbergen 2012; Stevens et al. 2015). Our focus was instead on performance-based attacks wherein a challenger alleges that "the incumbent has lost his touch with the people back home, doesn't work hard, doesn't stand on principle and changes his mind to please different people, has used the office for personal gain, [and] will say just about anything to get reelected" (Johnson 2007, 65). This seems to be an especially good basis for evaluation when the target is an incumbent, as is the case in our experimental manipulations. ${ }^{16}$

12. The results reported below emphasize the key role played by party in shaping voters' reactions to campaign communications. Although it is possible that such a response may have been due in some measure to the priming of partisanship by our background questionnaire, the overall centrality of party cues and stereotypes in contemporary American politics (Dolan 2014; Iyengar, Jackman, and Hahn 2008; Stevens et al. 2015) leads us to believe that this effect was probably not large, if it existed at all.

13. While each candidate's party affiliation and status as challenger or incumbent was noted, the biosketches were crafted as to ensure that the two portrayals were essentially equivalent.

14. On the potential persuasive effects of negative direct mail, see Gerber, Kessler, and Meredith(2011).

15. We were assisted in writing the candidate biographies, attacks, and responses by an experienced campaign consultant who has worked on numerous legislative races over the years. Additional details about this survey can be found in our online appendices at http://dx.doi.org/10.1017/ S1743923X15000550.

16. As candidates frequently do attack one another for reasons having little to do with the policy differences between them, we chose to focus on performance (basically a valence issue as operationalized here - that is, a desire for honest and civic-minded representation that is 
The attack employed in this study (taking advantage) charged the incumbent with "helping himself to other people's money" in a number of ways: voting for pay raises, using party money to finance a family vacation, renting office space from his brother at inflated prices, overbilling clients for professional services, and channeling no-bid government contracts to campaign donors. ${ }^{17}$ These allegations, regarding matters that are clearly relevant to the target's performance as an elected representative, were made in language that might not be considered "uncivil" but comes very close to that line by using such emotionally charged terms as "corrupt," "immoral," and "deserves to be in jail more than in Congress." 18 Each participant read the text for taking advantage plus one of the five responses described earlier (see online Appendix B for more information). The impact of candidate gender was tested using a within-subjects design with the following parameters:

$1 \quad$ (attack type $) \times 5$ (response type $) \times 4 \quad$ (party affiliation + gender combinations $)=$ a total of 20 treatment groups, to which participants were randomly assigned.

Specifically, for each attack-response pair, four treatment conditions were created: male Republican incumbent attacked by female Democrat, female Republican incumbent attacked by male Democrat, male Democratic incumbent attacked by female Republican, and female Democratic incumbent attacked by male Republican. ${ }^{19}$

presumably shared by most voters regardless of their partisan/ideological leanings or their gender). This allowed us to combine Democratic and Republican candidates, as well as men and women, without having to worry much about interactions between either party affiliation or gender and the content of the exchange.

17. As a manipulation check (see Mutz 2011), we wanted to determine whether respondents perceived our simulated attack ad as being negative, as intended. In fact, $26.6 \%$ indicated that the criticisms made in the ad were "too negative and should not be made publicly," $65.4 \%$ said they were "negative but acceptable within the context of a competitive political campaign," and just $8.0 \%$ felt the ad was "not really negative at all." This latter proportion did not vary in any systematic way across either partisan categories (though the figure was higher at $27.8 \%$ among those who replied "don't know" to our party identification question) or gender (women were about six points more inclined than men to see the add as "too negative" and two points less apt to perceive it as "not really negative at all"). Additional details are provided in online Appendix A.

18. According to Fridkin and Kenney (2008), relevant and uncivil ads have the greatest impact on candidate evaluations (especially if the candidate happens to be male; see Fridkin, Kenney, and Woodall 2009).

19. Our randomization process appears to have been successful. No statistically significant differences $(\mathrm{p}<.10)$ were observed among members of the 20 groups with regard to demographics, partisanship, ideological self-placement, or baseline candidate preferences (vote choice, favorability ratings). In addition, there were no statistically significant differences for these variables among respondents assigned to the five response types. If differences are found across research groups, we can therefore be confident that these are driven by exposure to the experimental stimuli. 


\section{RESULTS}

\section{Effectiveness of the Attack}

Do negative ads work? This one clearly did, at least in terms of its initial impact. Looking at all respondents, the top row in Table 1 indicates that support for the incumbent dropped 18.1 points (from 50.3 to $32.2 \%$ ), ${ }^{20}$ while his/her favorability score fell by more than a point and a half on the 7-point scale (from 4.624 to 3.000) following the attack; both of these changes are statistically significant $(\mathrm{p}<.001)^{21}$ and substantively large. While some backlash is evident in the fact that sponsor favorability declined by 0.512 points (from 4.631 to $4.119, \mathrm{p}<.001$ ), there appears to be a sizeable net advantage in these instances to going negative.

According to $\boldsymbol{H}_{1}$, a well-crafted attack made by any candidate should be more effective with voters who share that candidate's party affiliation. As shown in rows 2-4 of Table 1, however, the attack significantly altered the vote intentions of the target's co-partisans (a decline of 29.9 points) and independents ( -22.4 points), while the preferences of those identifying with the attacker's party remained largely unchanged $(-4.0$ points, $\mathrm{p}=0.122$ ). While this result might seem counterintuitive, it undoubtedly reflects the fact that few of the latter group (just $11.1 \%$ ) planned to vote for the target in the first place, based solely on the candidates' biosketches; in other words, there was considerably more potential for movement among the target's co-partisans (and, to a lesser degree, among independents, $56.4 \%$ of whom initially said they would vote to reelect).

Changes in candidate favorability were more evenly balanced across the three groups, with incumbent ratings dropping about 1.7 points (on a 7point scale) among both fellow and opposing partisans and nearly 1.3 points among independents. Similarly, backlash against the attacking challenger was greatest among the incumbent's co-partisans $(-0.643$ points) but evident among the attacker's co-partisans and independents $(-0.415$ and -0.467 , respectively) as well. Such backlash aside, however, our results indicate that shared partisanship does not always shield candidates from the impact of hard-hitting criticism by their

20. Respondents who did not indicate a preference are included in the analysis (and classified as not supporting the incumbent) rather than treated as missing. For more complete results, see online Appendix A.

21. We opt for t-tests rather than regression models in an effort to simplify the interpretation of our results and to capture both (a) the change in support for candidates across time and (b) the level of support for each candidate during each stage of the experiment. 
Table 1. Effects of attack ads on vote choice and candidate evaluations, by shared partisanship and shared gender

\begin{tabular}{|c|c|c|c|c|c|c|}
\hline & \multicolumn{2}{|c|}{ Vote for Incumbent } & \multicolumn{2}{|c|}{ Favorability, Incumbent } & \multicolumn{2}{|c|}{ Favorability, Challenger } \\
\hline All respondents & & \multicolumn{2}{|c|}{ 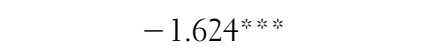 } & \multicolumn{2}{|c|}{ 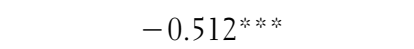 } \\
\hline $\begin{array}{l}\text { Same PID as incumbent/ } \\
\text { target }\end{array}$ & \multicolumn{2}{|c|}{$-29.9^{-2}$} & \multicolumn{2}{|c|}{ 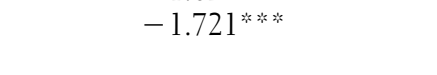 } & \multicolumn{2}{|c|}{ 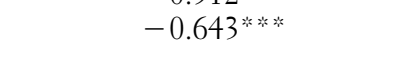 } \\
\hline $\begin{array}{l}\text { Opposite PID as } \\
\text { incumbent/target }\end{array}$ & \multicolumn{2}{|c|}{-4.0} & \multicolumn{2}{|c|}{$-1.755^{* * * * *}$} & \multicolumn{2}{|c|}{ 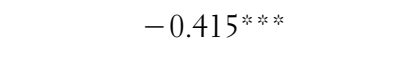 } \\
\hline Independents & \multirow{2}{*}{\multicolumn{2}{|c|}{ 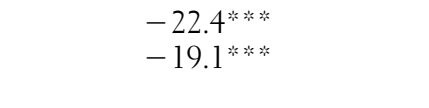 }} & \multirow{2}{*}{\multicolumn{2}{|c|}{ 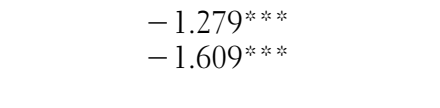 }} & \multirow{2}{*}{\multicolumn{2}{|c|}{$\begin{array}{l}-0.467^{* \cdots * *} \\
-0.472^{* \cdots * *}\end{array}$}} \\
\hline $\begin{array}{l}\text { Same gender as incumbent/ } \\
\text { target }\end{array}$ & & & & & & \\
\hline \multirow{2}{*}{$\begin{array}{l}\text { Opposite gender as } \\
\text { incumbent/target }\end{array}$} & \multicolumn{2}{|c|}{ 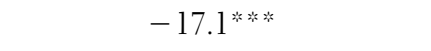 } & \multicolumn{2}{|c|}{$-1.639^{*}$ 头棌 } & \multicolumn{2}{|c|}{ 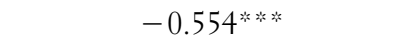 } \\
\hline & $\begin{array}{c}\text { Male } \\
\text { Incumbent, } \\
\text { Female } \\
\text { Attacker }\end{array}$ & $\begin{array}{c}\text { Female } \\
\text { Incumbent, } \\
\text { Male Attacker }\end{array}$ & $\begin{array}{c}\text { Male } \\
\text { Incumbent, } \\
\text { Female } \\
\text { Attacker }\end{array}$ & $\begin{array}{c}\text { Female } \\
\text { Incumbent, } \\
\text { Male Attacker }\end{array}$ & $\begin{array}{c}\text { Male } \\
\text { Incumbent, } \\
\text { Female } \\
\text { Attacker }\end{array}$ & $\begin{array}{c}\text { Female } \\
\text { Incumbent, } \\
\text { Male Attacker }\end{array}$ \\
\hline All respondents & 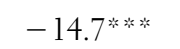 & 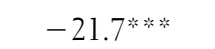 & 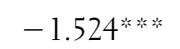 & 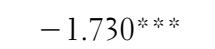 & $-0.568^{\text {粆棌 }}$ & 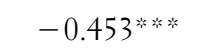 \\
\hline $\begin{array}{l}\text { Same PID as } \\
\text { incumbent/target }\end{array}$ & 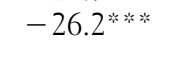 & -33.9 * & 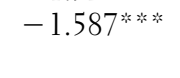 & -1.864 米皮 & 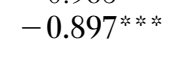 & $-0.373^{* * *}$ \\
\hline $\begin{array}{l}\text { Opposite PID as } \\
\text { incumbent/target }\end{array}$ & +2.4 & $-10.0^{* * *}$ & 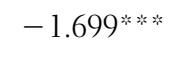 & 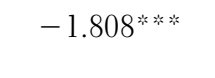 & 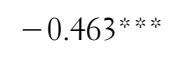 & $-0.369^{* * * * *}$ \\
\hline Independents & $-22.0 * *$ & $-23.0 * *$ & $-1.198^{\text {等称 }}$ & $-1.378^{\text {皮等 }}$ & $-0.253^{*}$ & $-0.730^{*}$ \\
\hline $\begin{array}{l}\text { Same gender as incumbent/ } \\
\text { target }\end{array}$ & $-15.7^{* * *}$ & 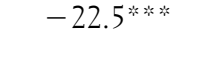 & $-1.349^{* * * *}$ & 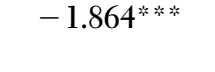 & 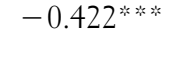 & 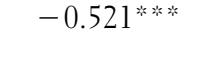 \\
\hline $\begin{array}{l}\text { Opposite gender as } \\
\text { incumbent/target }\end{array}$ & $-13.8^{* * *}$ & $-20.9^{* \ldots * \ldots}$ & 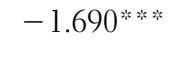 & -1.582 皮的 & 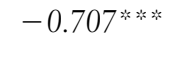 & -0.379 米类 \\
\hline
\end{tabular}

Note: For vote choice, difference is calculated as proportion (post-attack vote) minus proportion (baseline vote); values have been converted to percentages. For favorability, difference is calculated as mean (post-attack) minus mean (baseline). Significance tests are 2-tailed. For the effect of the attack, " $\mathrm{p}<.05$; $* * \mathrm{p}<.01 ; * * * \mathrm{p}<.001$. For significant differences across candidate gender, italics $\mathrm{p}<.05$; bold $\mathrm{p}<.01$ 
opponents. This is not to say that party plays no role in determining how people react to campaign ads; it merely suggests that when voters encounter negative information about a candidate whom they are otherwise inclined to support (especially absent a response from that candidate), shared partisanship may not be enough to prevent a loss of support.

The results in the bottom half of Table 1 more directly address our central research question of whether voters are either more or less receptive to negative ads by male or female candidates in mixed-gender races. For the full sample, we can see that our hypothetical female challenger fared less well than her male opponent in every category: her attack produced a smaller decline in both incumbent vote share $(-14.7$ percentage points versus -21.7 for the male) and incumbent favorability $(-1.524$ points versus -1.730$)$, while generating greater backlash in terms of lower favorability scores for herself $(-0.568$ points vs. -0.453$)$. While this pattern suggests that going negative may be slightly less effective for women than for men, the effects of the attack, when delivered by our female candidate, were not significantly different from the effects of the attack when it was made by her male counterpart. ${ }^{22}$

Following Krupnikov and Bauer (2014), $\boldsymbol{H}_{2}$ posits that attacks by women will be less effective than those made by men among the incumbent's fellow partisans. We find some evidence of this but not in every instance and not always in the manner anticipated. Among the incumbent's copartisans, where $\boldsymbol{H}_{2}$ predicts that women will be at a disadvantage, the only significant gender difference is for challenger favorability: there was a larger backlash against our female attacker $(-0.897$ points) compared with the male $(-0.373$ points, $\mathrm{p}<.01)$. Also, contrary to $\boldsymbol{H}_{2}$, we see in Table 1 that women challengers had less success than men in reducing the incumbent's vote share among their own fellow partisans $(+2.4$ points versus -10 for the male, $\mathrm{p}<.05)$. Interestingly, among independents there was less backlash against the female attacker in terms of diminished favorability $(-0.253$ points versus -0.730 for the male, $\mathrm{p}<.01)$; although the same result is not evident for vote preference and incumbent favorability, this suggests that independents may in some instances be even less likely than partisans to invoke traditional gender stereotypes.

22. Because the number of respondents involved is almost always small, any test of statistical significance may lead us to overlook meaningful differences between groups. We hope that future studies will be able to overcome this limitation of our own work. 
Overall, the findings here provide little support for $\boldsymbol{H}_{2}$. Whereas an attack by the woman may have been somewhat less effective than one by the man, differences between the two were small, inconsistent, and evident at times among fellow and opposing partisans alike (with independents exhibiting a modest tendency in the other direction).

What, then, about shared gender? According to $\boldsymbol{H}_{3}$, the attack should have had a greater effect among voters who share the attacker's gender. Rows 5-6 of Table 1 show that the attack caused the incumbent/target to lose ground in terms of both vote share and favorability - and, for the most part, this was equally true (statistically speaking) among those who shared the target's gender and those who did not. There are, however, three exceptions, all involving significantly greater movement ${ }^{23}$ in favorability ratings among female respondents (see the bottom half of Table 1): When a female candidate attacked a male incumbent, the effect on incumbent favorability was more pronounced among women $(-1.690$ versus -1.349 for men, $\mathrm{p}<.05)$, as was backlash against the attacker $(-0.707$ versus -0.422 for men, $\mathrm{p}<0.05)$. While we predicted that voters would react differently to criticism depending on whether it is directed at in-group (same-sex) or out-group candidates, at least for this sample and this particular campaign attack, no such bias is evident. ${ }^{24}$

Examining differences across male and female candidates, we again find the impact of shared gender to be inconsistent. An attack by the male candidate is significantly more effective than one by the female in two instances: (a) target favorability drops more sharply among women voters when a male challenger attacks a female incumbent ( -1.864 points) than it does among men when a female challenger attacks a male incumbent $(-1.349, \mathrm{p}<.01)$; and (b) backlash in the form of lower challenger favorability is less pronounced among men voters when a male candidate attacks $(-0.379)$ than it is among women when a female candidate attacks $(-0.707, \mathrm{p}<.05)$. Shared gender does not appear to matter much in other areas, including the all-important category of vote intention.

23. The results of these significance tests are not shown in Table 1.

24. Baseline support for the candidates did not vary systematically by voter gender. For example, based on the biosketches alone, a slight majority of both men and women said they would vote for the female candidate as either an incumbent or a challenger; likewise, the baseline favorability score was slightly higher for the female candidate among men and women voters alike. 


\section{Effectiveness of Responses}

As reported elsewhere (Craig, Rippere, and Grayson 2014), four of the five active responses examined here - all except accusations of mudslinging were more or less equally effective at mitigating the damage done by an attack. With little theoretical reason to believe otherwise, we hypothesized $\left(\boldsymbol{H}_{4}\right)$ that no response type would be more or less effective for women than for men. The results in Table 2 bear out that expectation, with two limited exceptions noted:

- Denials seemed to work better for male incumbents, especially in terms of recovered vote share $(+23.1$ points from post-attack to post-response versus +12.9 for women).

- Female incumbents fared better when justifying their actions to voters $(+32.2$ percentage points vote share versus +17.5 for men; +1.220 points incumbent favorability versus +0.857 , and -0.898 points challenger favorability versus -0.508 , for men).

However, none of the gender differences shown in the top portion of Table 2 are statistically significant at $\mathrm{p}<.05$ or better; thus, for the most part, $\boldsymbol{H}_{4}$ is clearly confirmed for each of our dependent variables. ${ }^{25}$

Our next hypothesis $\left(\boldsymbol{H}_{4}\right)$ states that any response, whether delivered by a man or a woman, will be most effective among the incumbent/responder's fellow partisans. Looking at the bottom half of Table 2, we find this to be generally true. With regard to vote preference (columns 1 and 2), denials, counterattacks, and justifications produced significant $(\mathrm{p}<.05)$ gains among co-partisans for women and men alike - but not, in the majority of cases, among opposing partisans or independents. In contrast, counterimaging and accusations of mudslinging failed to generate significant change in any partisan category.

The pattern for incumbent favorability is different, at least with respect to the effects of shared partisanship. First, four of the five responses (counterattack being the exception) were associated with improved ratings $(\mathrm{p}<.05)$ among fellow partisans for male and female incumbents alike. Second, however, significant or near-significant gains were also registered for some responses among opposing partisans (denials, counterimaging, and justifications for incumbents regardless of gender). Nevertheless, the results are generally consistent with $\boldsymbol{H}_{5}$ :

25. Examining the net effects of attack and response (i.e., where the candidates stood after participants heard from both sides) provides further confirmation of $\boldsymbol{H}_{4}$ (see online Appendix A). 
Table 2. Effects of response ads on vote choice and candidate evaluations, by incumbent's gender

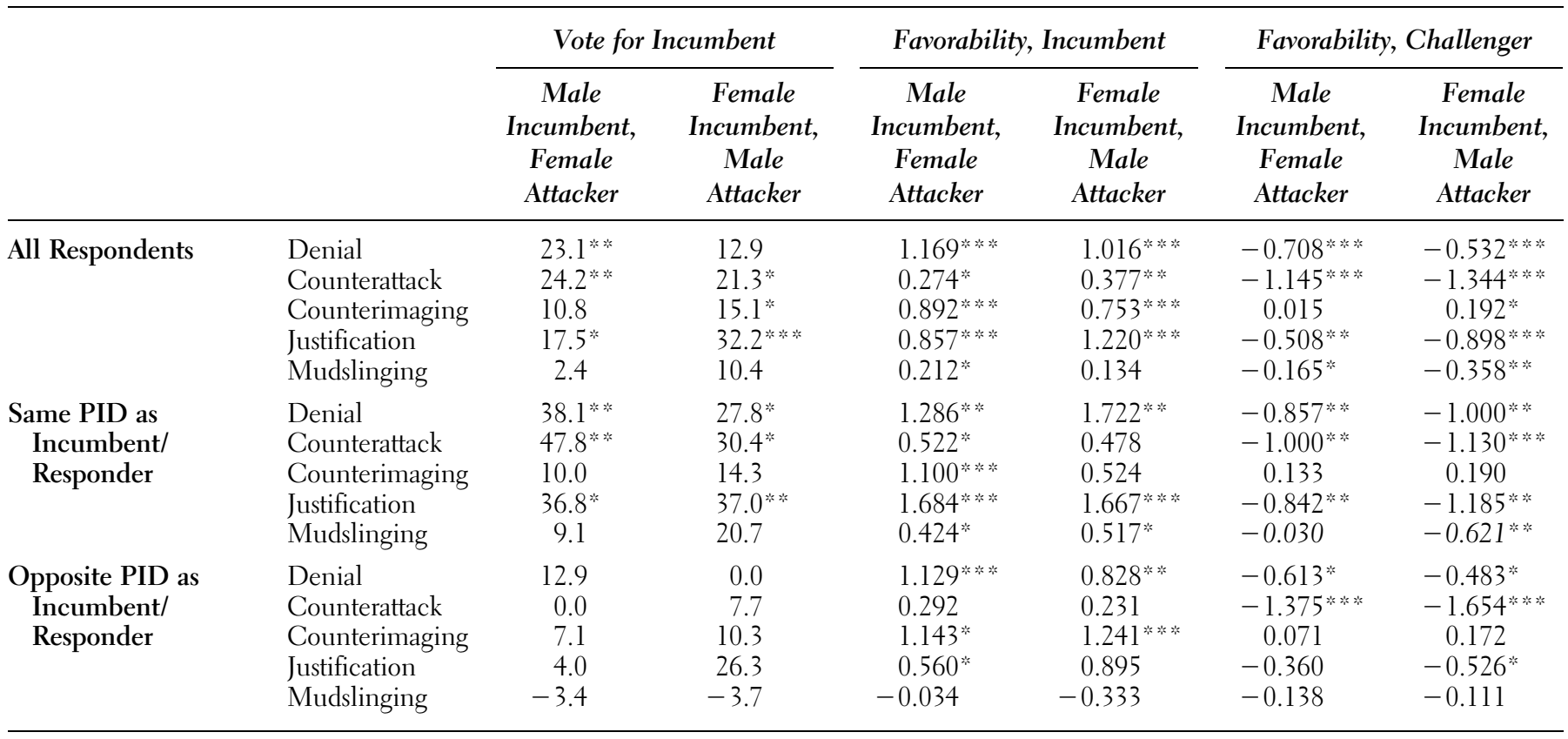


Table 2. Continued

\begin{tabular}{|c|c|c|c|c|c|c|c|}
\hline & & \multicolumn{2}{|c|}{ Vote for Incumbent } & \multicolumn{2}{|c|}{ Favorability, Incumbent } & \multicolumn{2}{|c|}{ Favorability, Challenger } \\
\hline & & $\begin{array}{c}\text { Male } \\
\text { Incumbent, } \\
\text { Female } \\
\text { Attacker }\end{array}$ & $\begin{array}{c}\text { Female } \\
\text { Incumbent, } \\
\text { Male } \\
\text { Attacker }\end{array}$ & $\begin{array}{c}\text { Male } \\
\text { Incumbent, } \\
\text { Female } \\
\text { Attacker }\end{array}$ & $\begin{array}{c}\text { Female } \\
\text { Incumbent, } \\
\text { Male } \\
\text { Attacker }\end{array}$ & $\begin{array}{c}\text { Male } \\
\text { Incumbent, } \\
\text { Female } \\
\text { Attacker }\end{array}$ & $\begin{array}{c}\text { Female } \\
\text { Incumbent } \\
\text { Male } \\
\text { Attacker }\end{array}$ \\
\hline Independents & $\begin{array}{l}\text { Denial } \\
\text { Counterattack } \\
\text { Counterimaging } \\
\text { Justification } \\
\text { Mudslinging }\end{array}$ & $\begin{array}{r}23.1 \\
26.7 \\
14.3 \\
15.8 \\
0.0\end{array}$ & $\begin{array}{l}20.0 \\
33.3 \\
21.7 \\
30.8 \\
18.2\end{array}$ & $\begin{array}{c}1.077^{*} \\
-0.133 \\
0.429 \\
0.421 \\
0.217\end{array}$ & $\begin{array}{l}0.533 \\
0.500 \\
0.348 \\
0.769 \\
0.273\end{array}$ & $\begin{array}{l}-0.692^{*} \\
-1.000^{* * *} \\
-0.190 \\
-0.368 \\
-0.391^{*}\end{array}$ & $\begin{array}{l}-0.067 \\
-1.083^{*} \\
0.217 \\
-0.846^{*} \\
-0.273\end{array}$ \\
\hline
\end{tabular}

Note: For vote choice, difference is calculated as proportion (post-response vote) minus proportion (post-attack vote); values have been converted to percentages. For favorability, difference is calculated as mean (post-response) minus mean (post-attack). Significance tests are 2-tailed. For the effect of the response, ${ }^{*} \mathrm{p}<$ $.05 ;{ }^{* *} \mathrm{p}<.01 ;{ }^{* * *} \mathrm{p}<.001$. For significant differences across candidate gender, italics $\mathrm{p}<.05$; bold $\mathrm{p}<.01$. 
response messages of all types resonated more fully - though not exclusively - and to an approximately equal degree for men and women among the responding candidate's fellow partisans.

Challenger favorability tells a more complex story, with some new variations on the broader theme. For the sample as a whole, four of the five responses (counterimaging being the exception) produced a significant decline in challenger favorability. As it happens, this decline was not always greatest among the incumbent/responder's fellow partisans. Counterattacks, for example, worked about as well among those who identified with the attacker's party and independents as they did among the incumbent's co-partisans - something that was true for both male and female candidates. The most interesting gender anomaly is that charges of mudslinging were more effective $(p<.05)$ for women candidates than for men among their co-partisans (see Table 2, row 10, last two columns). Still, post-response shifts in challenger favorability appear to be mostly in line with our earlier conclusions. Overall, our findings suggest that shared partisanship does play a positive, if not always a strong or consistent, role in shaping voters' reactions to response messages in a campaign, and these reactions do not vary systematically for participants according to whether the responding candidate is a man or a woman.

Finally, Table 3 examines the impact of shared gender on the effectiveness of our five responses. Contrary to $\boldsymbol{H}_{6}$, there is little here to suggest that any type of response was more (or less) effective among voters who were of the same gender as the incumbent/target. Rather, each response had similar effects on vote choice and candidate ratings for both men and women, regardless of the incumbent's gender. The only instance where a significant $(\mathrm{p}<.05)$ difference is observed between respondents who share the gender of the incumbent and those who do not is when the male incumbent employs a counterimaging response - and in this case, incumbent favorability increased less for in-group $(+0.500$ points among men $)$ than for out-group voters $(+1.273$ points among women). No other cross-group differences were significant. Likewise, in no instance do we observe a difference between the performance of female and male incumbents that is significant at $\mathrm{p}<.05$. Overall, these results appear to affirm our earlier conclusion that the gender of respondents and candidates has little influence on a political campaign.

To be sure that an interaction effect between respondents' party and gender is not obscuring some relationships between gender and the 
Table 3. Effects of response ads on vote choice and candidate evaluations, by shared gender

\begin{tabular}{|c|c|c|c|c|c|c|c|}
\hline & & \multicolumn{2}{|c|}{ Vote for Incumbent } & \multicolumn{2}{|c|}{ Favorability, Incumbent } & \multicolumn{2}{|c|}{ Favorability, Challenger } \\
\hline & & $\begin{array}{c}\text { Male } \\
\text { Incumbent, } \\
\text { Female } \\
\text { Attacker }\end{array}$ & $\begin{array}{c}\text { Female } \\
\text { Incumbent, } \\
\text { Male } \\
\text { Attacker }\end{array}$ & $\begin{array}{c}\text { Male } \\
\text { Incumbent, } \\
\text { Female } \\
\text { Attacker }\end{array}$ & $\begin{array}{c}\text { Female } \\
\text { Incumbent, } \\
\text { Male } \\
\text { Attacker }\end{array}$ & $\begin{array}{c}\text { Male } \\
\text { Incumbent, } \\
\text { Female } \\
\text { Attacker }\end{array}$ & $\begin{array}{c}\text { Female } \\
\text { Incumbent, } \\
\text { Male } \\
\text { Attacker }\end{array}$ \\
\hline $\begin{array}{l}\text { Same Gender as } \\
\text { Incumbent/ } \\
\text { Responder }\end{array}$ & $\begin{array}{l}\text { Denial } \\
\text { Counterattack } \\
\text { Counterimaging } \\
\text { Justification } \\
\text { Mudslinging }\end{array}$ & $\begin{array}{r}28.1^{*} \\
21.9 \\
3.1 \\
14.7 \\
5.6\end{array}$ & $\begin{array}{l}11.8 \\
21.6 \\
0.0 \\
36.8^{* *} \\
11.4\end{array}$ & 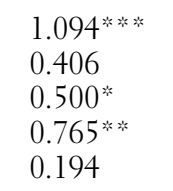 & 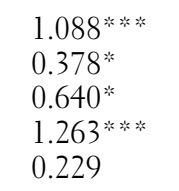 & $\begin{array}{l}-0.781^{\text {*** }} \\
-1.031^{* * * *} \\
-0.063 \\
-0.618^{* * *} \\
-0.222\end{array}$ & 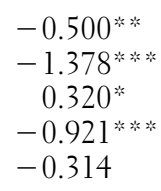 \\
\hline $\begin{array}{l}\text { Opposite Gender as } \\
\text { Incumbent/ } \\
\text { Responder }\end{array}$ & $\begin{array}{l}\text { Denial } \\
\text { Counterattack } \\
\text { Counterimaging } \\
\text { Justification } \\
\text { Mudslinging }\end{array}$ & $\begin{array}{l}18.2 \\
26.7^{*} \\
18.2 \\
20.7 \\
0.0\end{array}$ & $\begin{array}{l}14.3 \\
20.8 \\
22.9 * \\
23.8 \\
9.4\end{array}$ & 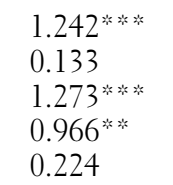 & 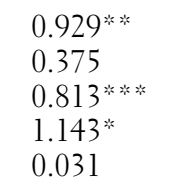 & $\begin{array}{l}-0.636^{* * *} \\
-1.267 * \cdots \cdots \\
0.091 \\
-0.379 \\
-0.122\end{array}$ & $\begin{array}{l}-0.571^{*} \\
-1.292^{* * *} \\
0.125 \\
-0.857^{*} \\
-0.406 *\end{array}$ \\
\hline
\end{tabular}

Note: For vote choice, difference is calculated as proportion (post-response vote) minus proportion (post-attack vote); values have been converted to percentages. For favorability, difference is calculated as mean (post-response) minus mean (post-attack). Significance tests are 2-tailed. ${ }^{*} \mathrm{p}<.10$; *** $\mathrm{p}<.05$; ${ }^{* * * *} \mathrm{p}<.01$. For the effect of the response, ${ }^{*} \mathrm{p}<.05 ;{ }^{* * *} \mathrm{p}<.01 ;{ }^{* * * *} \mathrm{p}<.001$. For significant differences across candidate gender, italics $\mathrm{p}<.05 ;$ bold $\mathrm{p}<.01$. 
effectiveness of our ads, we regressed shared gender and shared partisanship on variables measuring the effect of the attack (or response - that is, the values measuring the difference in vote for incumbent, incumbent favorability, and challenger favorability from tl to $t 2$ and from $t 2$ to $t 3$ ). We ran these regressions for each ad individually and across candidate genders (testing the results for male and female candidates separately). The results of these analyses are consistent with those for our t-tests.

\section{DISCUSSION}

Although there is evidence that negative advertising "works" at least some of the time, it has been suggested that going negative poses a special risk for female candidates because it violates expectations about appropriate behavior that are rooted in traditional gender stereotypes held by many voters. If this is true, then women could be at a similar disadvantage when they answer a negative with a negative - that is, when they respond in kind to an opponent's attack - which is precisely the strategy that is preferred by many (or perhaps even most) campaign professionals. Our study has addressed these possibilities using data from an Internetbased survey experiment with a national sample of registered voters. Specifically, we examined gender differences in the effectiveness of (1) a performance-based negative attack made by a challenger against an incumbent of the opposite sex in a hypothetical race for the U.S. House; and (2) five distinct responses to that attack, some of them (counterattack, accusations of mudslinging) more negative in tone than others.

Looking at our sample as a whole, we learned that party mattered more than candidate gender in shaping voters' reactions to both attack and response, though neither shared partisanship nor shared gender had a strong or consistent impact overall. As for the question of whether negative ads are noticeably less effective for women than for men, the answer appears to be no: among all respondents, the attack moved fewer votes and had a marginally weaker impact on favorability ratings when it was made by our female candidate than when it was made by her male counterpart; however, these differences were not statistically significant at conventional levels. Taking our cue from Krupnikov and Bauer (2014), we posited that women would incur a greater penalty for going negative but only among the incumbent/target's fellow partisans. For the most 
part, the attack worked about as well for one candidate as it did for the other among voters of all partisan stripes and both genders.

With little guidance from the literature, we hypothesized that the effectiveness of our five response types would be similar for women and men. While there were hints that denials may work better for men and justifications better for women, the mudslinging charge yielded unimpressive results for both male and female incumbents. In general, however, gender differences in our study were once again both small and inconsistent. We also expected to find that any response, whether made by a man or a woman, would be most effective among the incumbent/ responder's fellow partisans $\left(\boldsymbol{H}_{5}\right)$. Although this was true in most cases, there were a number of exceptions, and the overall pattern is consistent with the expectations laid out in our hypothesis. Finally, as with the attacks, we found little to no evidence that shared gender matters in the effectiveness of a response.

For this particular attack and these five responses most voters (regardless of their gender) reacted in a similar fashion to both male and female candidates. Most importantly, there is only slight evidence to indicate that women are held to a different standard when they choose to go negative proactively or when they answer an attack by criticizing their attacker. Our analysis suggests that some types of responses may work better for either men or women with certain groups of voters, and the same thing is almost certainly true for attacks as well. Given the inability of scholars to faithfully re-create a political campaign in the laboratory (Gadarian and Lau 2011), questions such as these can only be answered through an accumulation of research that employs a healthy mix of observational and experimental (lab, field, and survey) designs (see Arceneaux 2010).

Indeed, there are several potentially important campaign elements that we were unable to examine in this study (see Craig, Rippere, and Grayson 2014 for a more complete discussion). One that may have different implications for men and women is the role of repetition. Our participants viewed a single attack followed by a single response, which represents a severely truncated version of the communication that occurs over the course of a typical campaign. Judging from the barrage of advertising to which voters are exposed in virtually any high-visibility, high-expenditure contest, political professionals are strong believers in the value of repetition (see Craig and Hill 2011, 135-38). At least one recent study confirms that belief while also indicating that too much repetition of a negative ad over too short a period of time can backfire on 
the sponsor candidate (Fernandes 2013). In addition, repeated exposure to negative ads may create a backlash against the sponsor among women voters (but not necessarily men; see King and McConnell 2003). We encourage future scholars to determine whether this still (or typically) is the case today and whether the reactions of men and women voters to message repetition vary with the gender of the candidate doing the attacking. While our study is one bit of good news for those who would like to see a level playing field for all politicians regardless of gender, there remains much work to be done before we can say with confidence that this has been achieved in the area of campaign communication.

\section{SUPPLEMENTARY MATERIAL}

To view supplementary material for this article, please visit http://dx.doi. org/10.1017/S1743923X15000550.

Stephen C. Craig is Professor of Political Science at the University of Florida and director of UF's Graduate Program in Political Campaigning, Gainesville, FL: sccraig@ufl.edu; Paulina S. Rippere is Assistant Professor of Political Science at Jacksonville University, Jacksonville, FL: pripper@ ju.edu

\section{REFERENCES}

Ansolabehere, Stephen, and Shanto Iyengar. 1995. Going Negative: How Political Advertisements Shrink and Polarize the Electorate. New York: Free Press.

Arceneaux, Kevin. 2010. "The Benefits of Experimental Methods for the Study of Campaign Effects." Political Communication 27 (2): 199-215.

Bartels, Larry M. 2014. "Remembering to Forget: A Note on the Duration of Campaign Advertising Effects." Political Communication 31 (4): 532-44.

Brooks, Deborah J. 2010. "A Negativity Gap? Voter Gender, Attack Politics, and Participation in American Elections." Politics E Gender 6 (3): 319-4l.

- 2011. "Testing the Double Standard for Candidate Emotionality: Voter Reactions to the Tears and Anger of Male and Female Politicians." Journal of Politics 73 (2): $597-615$.

- 2013. He Runs, She Runs: Why Gender Stereotypes Do Not Harm Women Candidates. Princeton, NJ: Princeton University Press.

Buell, Emmett H., Jr., and Lee Sigelman. 2008. Attack Politics: Negativity in Presidential Campaigns since 1960. Lawrence: University Press of Kansas.

Cook Elizabeth A., Sue Thomas, and Clyde Wilcox, eds. 1994. The Year of the Woman: Myths and Realities. Boulder, CO: Westview Press.

Craig Stephen C., and David B. Hill, eds. 2011. The Electoral Challenge: Theory Meets Practice, 2nd ed. Washington, D.C.: CQ Press. 
Craig, Stephen C., and Paulina S. Rippere. 2014. "Political Trust and Negative Campaigns: Two Tests of the Figure-Ground Hypothesis." Politics and Policy 42 (5): 693-743.

Craig, Stephen C., Paulina S. Rippere, and Marissa Silber Grayson. 2012. "Attack and Response in Political Campaigns: An Experimental Study." Presented at the Annual Meetings of the Midwest Political Science Association, Chicago.

- 2014. "Attack and Response in Political Campaigns: An Experimental Study in Two Parts." Political Communication 31 (4): 647-74.

Dinzes, Deborah, Michael D. Cozzens, and George G. Manross. 1994. "The Role of Gender in 'Attack Ads': Revisiting Negative Political Advertising." Communication Research Reports 11 (1): 67-75.

Ditonto, Tessa M., Allison J. Hamilton, and David P. Redlawsk. 2014. “Gender Stereotypes, Information Search, and Voting Behavior in Political Campaigns." Political Behavior 36 (2): $335-58$.

Dolan, Kathleen. 2008. “Is There a 'Gender Affinity Effect' in American Politics?” Political Research Quarterly 61 (1): 79-89.

- 2014. "Gender Stereotypes, Candidate Evaluations, and Voting for Women Candidates: What Really Matters?” Political Research Quarterly 67 (1): 96-107.

Dolan, Kathleen, and Timothy Lynch. 2014. "It Takes a Survey: Understanding Gender Stereotypes, Abstract Attitudes, and Voting for Women Candidates." American Politics Research 42 (4): 656-76.

Druckman, James N., Erik Peterson, and Rune Slothuus. 2013. "How Elite Polarization Affects Public Opinion Formation.” American Political Science Review 107 (1): 57-79.

Fernandes, Juliana. 2013. "Effects of Negative Political Advertising and Message Repetition on Candidate Evaluation." Mass Communication and Society 16 (2): 268-91.

Fowler, Erika Franklin, and Travis N. Ridout. 2012. "Negative, Angry, and Ubiquitous: Political Advertising in 2012.” The Forum 10 (4): 51-61. http://www.documentcloud. org/documents/699752-negative-angry-and-ubiquitous-political.html (accessed March 2, 2016).

Franz, Michael M., Paul B. Freedman, Kenneth M. Goldstein, and Travis N. Ridout. 2008. Campaign Advertising and American Democracy. Philadelphia: Temple University Press.

Fridkin, Kim L., and Patrick J. Kenney. 2008. "The Dimensions of Negative Messages.” American Politics Research 36 (5): 694-723.

_. 2011. "Variability in Citizens' Reactions to Different Types of Negative Campaigns." American Journal of Political Science 55 (2): 307-325.

Fridkin, Kim L., Patrick J. Kenney, and Gina S. Woodall. 2009. "Bad for Men, Better for Women: The Impact of Stereotypes during Negative Campaigns." Political Behavior 31 (1): $53-77$.

Gadarian, Shana Kushner, and Richard R. Lau. 2011. "Candidate Advertisements." In Cambridge Handbook of Experimental Political Science, ed. James N. Druckman, Donald P. Green, James H. Kuklinski, and Arthur Lupia. Cambridge: Cambridge University Press.

Geer, John G. 2006. In Defense of Negativity: Attack Ads in Presidential Campaigns. Chicago: University of Chicago Press.

- "The News Media and the Rise of Negativity in Presidential Campaigns." PS: Political Science and Politics. 45 (3):422-427.

Gerber, Alan S., James G. Gimpel, Donald P. Green, Daron R. Shaw. 2011. "How Large and Long-Lasting are the Persuasive Effects of Televised Campaign Ads? Results from a Randomized Field Experiment.” American Political Science Review 105 (1): 135-50.

Gerber, Alan S., Daniel P. Kessler, and Marc Meredith. 2011. "The Persuasive Effects of Direct Mail: A Regression Discontinuity Based Approach." Journal of Politics 73 (1): $140-55$. 
Gordon, Ann, David M. Shafie, and Ann N. Cigler. 2003. "Is Negative Advertising Effective for Female Candidates? An Experiment in Voters' Uses of Gender Stereotypes." International Journal of Press/Politics 8 (3): 35-53.

Hayes, Danny. 2011. "When Gender and Party Collide: Stereotyping in Candidate Trait Attribution." Politics and Gender 7 (2): 133-65.

Herrnson, Paul S. and Jennifer C. Lucas. 2006. "The Fairer Sex? Gender and Negative Campaigning in U.S. Elections.” American Politics Research 34 (1): 69-94.

Hill, Seth J., James Lo, Lynn Vavreck, and John Zaller. 2013. "How Quickly We Forget: The Duration of Persuasion Effects from Mass Communication." Political Communication 30 (4): 521-47.

Hitchon, Jacqueline C., and Chingching Chang. 1995. "Effects of Gender Schematic Processing on the Reception of Political Commercials for Men and Women Candidates." Communication Research 22 (4): 430-58.

Iyengar, Shanto, Simon Jackman, and Kyu Hahn. 2008. "Polarization in Less than Thirty Seconds: Continuous Monitoring of Voter Response to Campaign Advertising." Presented at the Annual Meetings of the Midwest Political Science Association, Chicago.

Jamieson, Kathleen Hall. 1992. Dirty Politics: Deception, Distraction, and Democracy. New York: Oxford University Press.

Johnson, Dennis W. 2007. No Place for Amateurs: How Political Consultants are Reshaping American Democracy, 2nd ed. New York: Routledge.

Johnson-Cartee, Karen S., and Gary Copeland. 1991. Negative Political Advertising: Coming of Age. Hillsdale, NJ: Erlbaum.

King, James D., and Jason B. McConnell. 2003. "The Effect of Negative Campaign Advertising on Vote Choice: The Mediating Influence of Gender." Social Science Quarterly 84 (4): 843-57.

Krupnikov, Yanna, and Nichole M. Bauer. 2014. "The Relationship between Campaign Negativity, Gender and Campaign Context.” Political Behavior 35 (1): 167-88.

Lau, Richard R., and Gerald M. Pomper. 2004. Negative Campaigning: An Analysis of U.S. Senate Elections. Lanham, MD: Rowman and Littlefield.

Lau, Richard R., and Ivy Brown Rovner. 2009. "Negative Campaigning." Annual Review of Political Science 12: 285-306.

Lavine, Howard G., Christopher D. Johnston, and Marco R. Steenbergen. 2012. The Ambivalent Partisan: How Critical Loyalty Promotes Democracy. New York: Oxford University Press.

Mattes, Kyle, and David P. Redlawsk. 2014. The Positive Case for Negative Campaigning. Chicago: Chicago University Press.

McGraw, Kathleen M. 1990. "Avoiding Blame: An Experimental Investigation of Political Excuses and Justification.” British Journal of Political Science 20 (1): 119-29.

McGraw, Kathleen M., Samuel Best, and Richard Timpone. 1995. "What They Say or What They Do?' The Impact of Elite Explanation and Policy Outcomes on Public Opinion." American Journal of Political Science 39 (1): 53-74.

Mutz, Diana C. 2011. Population-Based Survey Experiments. Princeton: Princeton University Press.

Nelson, Kjersten R. 2009. "If You Can't Say Something Nice: The Gender Dynamics of Negative Messaging." Ph.d. diss. University of Minnesota.

Panagopoulos, Costas. 2004. "Boy Talk/Girl Talk: Gender Differences in Campaign Communications Strategies." Women and Politics 26 (3-4): 1315-15.

Plutzer, Eric, and John F. Zipp. 1996. "Identity Politics, Partisanship, and Voting for Women Candidates.” Public Opinion Quarterly 60 (1): 30-57. 
Ridout, Travis N., and Glen R. Smith. 2008. "Free Advertising: How the Media Amplify Campaign Messages." Political Research Quarterly 61 (4): 598-608.

Rosenthal, Cindy Simon. 1995. "The Role of Gender in Descriptive Representation." Political Research Quarterly 48 (3): 599-611.

Sanbonmatsu, Kira. 2002. "Gender Stereotypes and Vote Choice." American Journal of Political Science 46 (1): 20-34.

Sanbonmatsu, Kira, and Kathleen Dolan. 2009. "Do Gender Stereotypes Transcend Party?" Political Research Quarterly 62 (3): 485-94.

Schneider, Monica C., and Angela L. Bos. 2014. "Measuring Stereotypes of Female Politicians." Political Psychology 35 (2): 245-66.

Sigelman, Lee, and Mark Kugler. 2003. "Why is Research on the Effects of Negative Campaigning So Inconclusive? Understanding Citizens' Perceptions of Negativity." Journal of Politics 65 (1): 142-60.

Stevens, Daniel, Barbara Allen, John Sullivan, and Eric Lawrence. 2015. "Fair's Fair? Principles, Partisanship, and Perceptions of the Fairness of Campaign Rhetoric." British Journal of Political Science 45 (1): 195-213.

Trent, Judith S., Robert V. Friedenberg, and Robert E. Denton, Jr. 2011. Political Campaign Communication: Principles and Practices, 7th ed. Lanham, NJ: Rowman and Littlefield.

Weaver Lariscy, Ruth Ann, and Spencer F. Tinkham. 1999. "The Sleeper Effect and Negative Political Advertising." Journal of Advertising 28 (4): 13-30.

West, Darrell M. 2014. Air Wars: Television Advertising and Social Media in Election Campaigns, 1952-2012, 6th ed. Washington, D.C.: CQ Press. 